.

\section{1} 2 3 14 15 19

\author{
Junguo $\mathrm{Ma}^{+}$, Yiyi Feng ${ }^{+}$, Siyu Jiang, Xiaoyu $\mathrm{Li}^{*}$
}

\title{
microcystin-LR \\ Altered cellular metabolism of HepG2 cells caused by
}

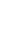

College of Life Science, Henan Normal University, Xinxiang, Henan 453007, China

${ }^{+}$These authors contributed equally to this work

8

9
16 17 8 20 21 \footnotetext{
* Corresponding author. Tel.: +86-373-3329390; Fax: +86-373-3329390
E-mail address: $\underline{\text { lixiaoyu65 @ 263.net }}$
} 


\section{Abstract}

This study aimed to evaluate the possible effects of microcystin-LR (MC-LR) exposure on the metabolism and drug resistance of human hepatocellular carcinoma (HepG2) cells. For this purpose, we first conducted an experiment to make sure that MC-LR could penetrate the HepG2 cell membrane effectively. The transcriptional levels of phase I (such as CYP2E1, CYP3A4, and CYP26B1) and phase II (such as EPHX1, SULTs, and GSTM) enzymes and export pump genes (such as MRP1 and MDR1) were altered by MC-LR-exposure for $24 \mathrm{~h}$, indicating that MC-LR treatment may destabilize the metabolism of HepG2 cells. Further research showed that the CYP inducers omeprazole, ethanol, and rifampicin inhibited cell viability, in particular, ethanol, a CYP2E1 inducer, induced ROS generation, lipid peroxidation, and apoptosis in HepG2 cells treated with MC-LR. The CYP2E1 inhibitor chlormethiazole inhibited ROS generation, mitochondrial membrane potential loss, caspase-3 activity, and cytotoxicity caused by MC-LR. Meanwhile, the results also showed that co-incubation with the ROS scavenger L-ascorbic acid and MC-LR decreased ROS levels and effectively prevented apoptosis. These findings provide an interesting mechanistic explanation of cellular metabolism associated with MC-LR, i.e., MC-LR-exposure exerted toxicity on HepG2 cells and induced apoptosis of HepG2 cells via promoting CYP2E1 expression and inducing excessive ROS in HepG2 cells. 


\section{Capsule abstract}

The linkage between CYP2E1-dependent oxidative stress and mitochondrial injury contributes to the toxic action of MC-LR on HepG2 cells.

Keywords: Microcystin-LR; HepG2; OATPs; metabolism-associated enzyme; drug resistance gene

\section{Introduction}

In recent years, cyanobacterial blooms have frequently occurred in eutrophic waterbodies worldwide, and the resulting release of cyanotoxins by some toxic cyanobacterial blooms not only leads to water pollution but also poses a potential health hazard to aquatic organisms and humans (O'Neil et al., 2012; Rastogi et al., 2014). Among these cyanotoxins, microcystins (MCs) are the most common of the toxins widely distributed in fresh water. They are produced by some cyanobacteria such as Anabaena, Aphanizomenon, Microcystis, Planktothrix, Oscillatoria, and Nostoc (Carmichael et al., 2001; van Apeldoorn et al., 2007). MCs are a group of cyclic heptapeptide toxins with the general structure cyclo (D)-Ala- X- (D)- erythrob- methyl- iso- Asp- Y- Adda- (D)- iso- Glu- N- meth- yldehydro- Ala, where X and Y represent positions occupied by the variable L-amino acids (Welker and von Döhren, 2006), and now more than 80 MC variants have been identified (Funari and Testai, 2008). Among these MCs, MC-LR is the most ubiquitous and frequently studied and it has been found to have hepatotoxicity in humans (Feng et al., 2011), other 
mammals (Li et al., 2009), birds (Peckova et al., 2009), and aquatic animals (Li et al., 2013; Ma et al., 2015a). Due to its high toxicity, the World Health Organization has recommended a drinking water guideline imposing an upper limit of $1.0 \mu \mathrm{g} \mathrm{L}^{-1}$ MC-LR for human daily consumption (WHO, 1998). Unfortunately, increasing studies have demonstrated that the concentrations of MCs can be much higher than this standard in cyanobacterial bloom-infested waters, such as $6.69 \mu \mathrm{g} \mathrm{L} \mathrm{L}^{-1}$ of MCs in the summer periods (Song et al., 2007) and $15.6 \mu \mathrm{g} \mathrm{L}{ }^{-1}$ in the wintertime (Xu et al., 2008) in Lake Taihu, China, 48.6 $\mu \mathrm{g} \mathrm{L}^{-1}$ in the blooming season in Argentina (Giannuzzi et al., 2011), and 10 to $500 \mu \mathrm{g} \mathrm{L}^{-1} \mathrm{MCs}$ in eutrophic lakes in America (Backer et al., 2010). Therefore, the MCs could be a health hazard to humans through drinking water or due to exposure via the food chain.

It has been demonstrated that acute intoxication with MCs can lead to human death (Azevedo et al., 2002), while chronic exposure to MCs has been verified to be one of the risk factors for human primary hepatocellular cancer (Nishiwaki-Matsushima et al., 1992). It is now well recognized that MCs are highly potent and specific inhibitors of serine/threonine protein phosphatases 1 and 2A (PP1 and PP2A) (Runnegar et al., 1993). Due to PP2A inhibition, the intracellular balance of phosphorylation/dephosphorylation is destroyed, and this causes hyperphosphorylation of some key structural or functional proteins and signaling molecules or pathways, for example, the mitogen-activated protein kinases (MAPKs) (Daily et al., 2010), which is directly related to the tumor-promoting activity of MCs (Campos and Vasconcelos, 2010). Simultaneously, excess intracellular reactive 
oxygen species (ROS) and oxidative stress caused by MCs have also been considered as another important mechanism of MCs toxicity (Li et al., 2003). However, studies regarding the effects of MCs on the cellular metabolism and drug resistance are limited.

It is well known that liver is the main target organ of MC toxicity (Nishiwaki-Matsushima et al., 1992). Therefore, hepatocytes or hepatoma cell line have been increasingly used as in vitro models to evaluate the toxicity of MCs. Human hepatocellular carcinoma (HepG2) cells can display the morphology and biochemical activities of healthy hepatocytes (Javitt, 1990) and hence have been widely used to evaluate the toxic effects of various toxicants on hepatocytes for many years (Van et al., 1997; Carvalho et al., 2014).

In recent years, gene expression alterations have been increasingly used in toxicological studies to provide an early and global answer regarding the molecular initiating events of the effects of toxicants (Brown and Botstein, 1999), and the utilization of transcriptional patterns is also a rational tool in molecular toxicology (Schmidt, 2002). Moreover, monitoring the transcriptional level of a panel of genes may help to reveal the role of genes in the response to toxicological stress and to elucidate the toxicological mechanism involved (Nuwaysir et al., 1999). In the present study, HepG2 cells were adopted to determine the transcriptional levels of organic anion transporter polypeptides (OATP1B1 and OATP1B3), metabolism-related enzymes such as cytochrome P450 (e.g., CYP2E1, CYP3A4, and CYP26B1), phase II (such as EPHX1, SULTs, NAT1 and GSTM) enzymes, and export pump genes (such 
as MRP1 and MDR1) using quantitative real-time PCR to reveal the possible

111 destabilization of cellular metabolism in HepG2 cells caused by MC-LR exposure.

112 The selected genes from phase I and phase II enzymes, and export pump genes were

113 play important role in the cellular metabolism or detoxification processes in the

114 mammalian cells. For example, among phase I CYP450 superfamily, subfamilies

115 CYP1, CYP2, and CYP3 are account for the metabolization and detoxification of 116 more than 80\% xenobiotics in animals and humans (Nelson, 2003; Singh et al., 2011),

117 and in subfamilies CYP3, CYP3A subfamily is major components in human liver 118 microsomes (Murray and Reidy 1990; Cantoni et al., 2003), and CYP3A plays a key 119 role in the metabolism of about $50 \%$ of all pharmaceuticals in use at present (Nelson, 120 2003).

121 Moreover, the CYP inducers omeprazole, ethanol, and rifampicin and the CYP 122 inhibitor chlormethiazole were used to investigate the role of CYPs in MC-LR 123 cytotoxicity. The results of the present study might provide valuable information on 124 the mechanisms of action of MC-LR on mammalian cells.

\section{Materials and methods}

\subsection{Cell culture and MC-LR exposure}

2016). MC-LR $\left(\mathrm{C}_{49} \mathrm{H}_{74} \mathrm{~N}_{10} \mathrm{O}_{12}, \geq 95 \%\right.$ purity, CAS 101043-37-2) were purchased from Express Technology Co., Ltd. China. 
trypsin, and then $5 \times 10^{3}$ or $1.5 \times 10^{4}$ cells per well were inoculated in 96 - or 6 -well plates in RPMI-1640 medium supplemented with $10 \%(\mathrm{v} / \mathrm{v})$ of heat-inactivated fetal bovine serum (FBS), $100 \mathrm{U} \mathrm{mL}^{-1}$ of penicillin, and $100 \mu \mathrm{g} \mathrm{mL}^{-1}$ of streptomycin in a $5 \% \mathrm{CO}_{2}$ humidified incubator at $37^{\circ} \mathrm{C}$. After $24 \mathrm{~h}$ of culture, MC-LR was added to each well at the concentrations specified below for each assay. The cells were cultured for an additional period of time as specified bellow for each test, and the medium and toxin concentrations were refreshed daily to maintain an approximately constant MC-LR concentration.

For the cell viability assay (96-well culture plate), (1) the culture medium was replaced with complete RPMI-1640 medium containing 0.1-10 $000 \mathrm{nM}$ MC-LR, and the cells cultured in complete medium without MC-LR served as the control for another $24 \mathrm{~h}$; (2) treatment groups containing $5 \mu \mathrm{M}$ MC-LR were grown with and without $10 \mu \mathrm{M}$ omeprazole (OME), $50 \mathrm{mM}$ ethanol (ETH), and $15 \mu \mathrm{M}$ rifampicin (RIF), and the cells cultured in complete medium without MC-LR served as the control for another $72 \mathrm{~h}$; (3) cultures containing 0-10 $\mu \mathrm{M}$ MC-LR were grown with and without $50 \mathrm{mM}$ ETH for another $24 \mathrm{~h}$; (4) cultures containing $5 \mu \mathrm{M}$ MC-LR were grown with and without $10 \mu \mathrm{M}$ chlormethiazole (CMZ) for another $72 \mathrm{~h}$; (5) cultures containing various concentrations of MC-LR $(0-100 \mu \mathrm{M})$ were grown for another $96 \mathrm{~h}$; (6) cultures containing $30 \mu \mathrm{M}$ MC-LR were grown with and without $10 \mu \mathrm{M} \mathrm{CMZ}$ for another $96 \mathrm{~h}$; (7) cultures containing $30 \mu \mathrm{M}$ MC-LR and $10 \mu \mathrm{M}$ L-ascorbic acid / 30 $\mu \mathrm{M}$ MC-LR were grown for another $72 \mathrm{~h}$.

For the flow cytometric assay, as described above, the treatment groups received 
0.1-10 $000 \mathrm{nM}$ MC-LR exposure, and the cells cultured without MC-LR served as the control for another $24 \mathrm{~h}$.

For the western blots and the quantitative real-time PCR (qPCR) assay, as described above, the culture medium in a 6-well culture plate was replaced with complete RPMI-1640 medium containing 0.1-10 $000 \mathrm{nM}$ MC-LR in the treatment groups or no MC-LR in the control for another $24 \mathrm{~h}$.

For measurement of intracellular ROS level, as described above, (1) the culture medium was replaced with complete RPMI-1640 medium containing $5 \mu \mathrm{M}$ MC-LR with and without $50 \mathrm{mM} \mathrm{ETH}$, and the cells were cultured for another $72 \mathrm{~h}$; (2) cultures containing $30 \mu \mathrm{M}$ MC-LR with and without $10 \mu \mathrm{M} \mathrm{CMZ}$ were grown for another $72 \mathrm{~h}$; and (3) cultures containing $30 \mu \mathrm{M}$ MC-LR with and without $10 \mu \mathrm{M}$ L-ascorbic acid were grown for another $72 \mathrm{~h}$.

For the lipid peroxidation assay, as described above, the culture medium was replaced with fresh complete RPMI-1640 medium. (1) Cultures containing $5 \mu \mathrm{M}$ MC-LR with and without $50 \mathrm{mM}$ ETH were grown for another $72 \mathrm{~h}$, and (2) cultures containing $30 \mu \mathrm{M}$ MC-LR with and without $10 \mu \mathrm{M} \mathrm{CMZ}$ were grown for another 48 h.

For the caspase-3 activity assay, the culture medium was replaced with fresh complete RPMI-1640 medium containing $30 \mu \mathrm{M}$ MC-LR with and without $10 \mu \mathrm{M}$ CMZ, and the cells were cultured for another $48 \mathrm{~h}$.

For Hoechst 33342 Staining, the culture medium was replaced with fresh complete RPMI-1640 medium containing $5 \mu \mathrm{M}$ MC-LR with and without $50 \mathrm{mM}$ 
ETH, and the cells were cultured for another $48 \mathrm{~h}$.

For the mitochondrial membrane potential (MMP) assay, in a 6-well culture plate, the culture medium was replaced with complete RPMI-1640 medium containing 30 $\mu \mathrm{M}$ MC-LR with and without $10 \mu \mathrm{M} \mathrm{CMZ}$, and the cells were cultured for another 48 h.

\subsection{Cell viability assay}

After the treatment time, the culture medium was replaced with $200 \mu \mathrm{L}$ of fresh medium containing $0.5 \mathrm{mg} \mathrm{mL}^{-1}$ MTT (Sigma, USA), and the cells were cultured for an additional $4 \mathrm{~h}$ at $37{ }^{\circ} \mathrm{C}$. Then, the cells were washed thrice with PBS, and the generated formazan was dissolved with $200 \mu \mathrm{L}$ DMSO. The cell viability measurement was performed as the described previously (Li et al., 2015).

\subsection{Flow cytometric analysis}

The cell cycle and apoptosis of HepG2 cells were evaluated using the PI/RNase Kit (Becton Dickinson, USA) and the FITC Annexin V Apoptosis Detection Kit (Becton Dickinson, USA), respectively, by flow cytometry (Becton Dickinson) as described previously ( $\mathrm{Li}$ et al., 2015).

\subsection{Western blot}

MC-LR uptake and entrance into HepG2 cells was determined by western blotting with antibodies against MC-LR as described by Xing et al. (2008). Briefly, 
the cells were washed twice with ice-cold PBS to remove MC-LR after $24 \mathrm{~h}$ of incubation with MC-LR (0-10 $000 \mathrm{nM})$ in a 6-well culture plate and then collected by digestion using $0.25 \%$ of trypsin and centrifugation at $4000 \mathrm{~g}$ for $8 \mathrm{~min}$. Western blot analysis of cellular lysates was performed as previously described (Ma et al., 2016). The following primary antibodies were employed: anti-MC-LR (1:300 dilution) (Alexis Biochemicals, Lausen, Switzerland) and anti-actin (1:3 000) (Proteintech, Wuhan, China). Goat anti-mouse IgG-alkaline phosphatase (1:20 000) was used as the secondary antibody. Immunoreactive protein bands were detected with a BCIP/NBT Alkaline Phosphatase Color Development Kit (Beyotime, Haimen, China). The figures presented were representative of at least three independent assays.

\subsection{RNA isolation and $q P C R$}

After 3, 6, 12, and $24 \mathrm{~h}$ of MC-LR exposure in a 6-well culture plate, the cells were collected as described above and stored at $-80{ }^{\circ} \mathrm{C}$ for the following RNA isolation.

Total RNA isolation, synthesis of first-strand cDNA, and qPCR were performed with an RNAiso Plus kit (Takara, Dalian, China), a PrimeScript ${ }^{\mathrm{TM}}$ Reagent Kit

216 (Takara), and a SYBR Premix Ex Taq II Kit (Takara), respectively, using methods described previously (Ma et al., 2015b). The expression of CYP1A1, CYP1A2, 
determined. The amount of target mRNA was normalized to GAPDH mRNA and was determined by the method of Livak and Schmittgen (2001). The primers designed for the qPCR reaction are listed in table 1.

\subsection{Measurement of intracellular ROS level}

The ROS level in HepG2 cells was measured according to the method of measuring the oxidative conversion of $2^{\prime}, 7^{\prime}$-dichlorofluorescein diacetate (DCFH-DA) to the fluorescent compound dichlorofluorescein (DCF) (Jia et al., 2006) as described previously by Ma et al. (2016).

\subsection{Lipid peroxidation assay}

Lipid peroxidation was determined by the method of thiobarbituric acid (TBA) (Ohkawa et al., 1979) as described previously (Li et al., 2015).

\subsection{Caspase-3 activity assay}

After MC-LR exposure described as above, the activity of caspase-3 was measured using a caspase activity kit (Beyotime, Haimen, China) according to the manufacturer's instructions as described previously by Ma et al. (2016).

\subsection{Hoechst 33342 staining}

After MC-LR exposure, the HepG2 cells were collected and washed twice with PBS, then stained with Hoechst 33342 (Sigma, USA) at a final concentration of $10 \mu \mathrm{g}$ 
$242 \mathrm{~mL}^{-1}$ for $30 \mathrm{~min}$ at $37^{\circ} \mathrm{C}$ in darkness. Cells were then washed twice with PBS and

243 immediately observed using a fluorescence microscope.

\subsection{Mitochondrial membrane potential assay}

The MMP was determined using the JC-1 probe by the manufacturer's instructions (Beyotime, Haimen, China). After exposure, the medium was discarded and the cells were then washed twice with PBS, after which $1 \mathrm{~mL}$ JC-1 working solution per well was added and incubated for $20 \mathrm{~min}$ at $37{ }^{\circ} \mathrm{C}$. Then, the JC-1 working solution was removed and washed twice with JC-1 staining buffer. Later, 2 $\mathrm{mL}$ of medium was added and MMP was assessed using a fluorescence microscope.

\subsection{Statistical analysis} considered statistically significant was set at $P$ value $<0.05$.

\section{Result} cells

The viability of HepG2 cells determined after exposure to MC-LR is depicted in cells exposed for $24 \mathrm{~h}$. The results of flow cytometric analysis with PI and annexin 
V/PI staining showed that the 0.1-10 $000 \mathrm{nM}$ MC-LR-exposure for $24 \mathrm{~h}$ did not alter the cell cycle (Supplemental Fig. 2) and apoptosis (Supplemental Fig. 3) of HepG2 cells, respectively.

\subsection{Detection of MC-LR entrance into HepG2 cells}

The result of the western blot assay showed that MC-LR entered HepG2 cells in a concentration-dependent pattern (Fig. 1). Indeed, our results from qPCR showed that HepG2 cells expressed $O A T P 1 B 1$ and $O A T P 1 B 3$, which are known to transport MC-LR. The expression levels of both $O A T P 1 B 1$ and $O A T P 1 B 3$ in HepG2 cells were promoted in the MC-LR-treated groups when compared to the control groups except for OAPTIB3 in the $5000 \mathrm{nM}$ group at 12 or $24 \mathrm{~h}$ and $10000 \mathrm{nM}$ at $24 \mathrm{~h}$ (Supplemental Fig. 4 A, B).

3.3. The transcriptional alteration of phase I and phase II genes in HepG2 cells after 24 h of MC-LR exposure

More than $90 \%$ of drugs and xenobiotic compounds are metabolized and detoxified by phase I and phase II enzymes; consequently, we wanted to determine whether phase I and phase II played a role after $24 \mathrm{~h}$ of MC-LR exposure. The results of qPCR showed that the transcription levels of $C Y P 2 E 1$ and $C Y P 26 B 1$ were generally up-regulated in the MC-LR-treated groups in comparison with the control (Fig. 2 A, Supplemental Fig. 5 G). However, CYP3A4 transcription was suppressed in higher concentration groups (5 000 and $10000 \mathrm{nM}$ ) in the early periods of MC-LR 
exposure (from 3 to $6 \mathrm{~h}$ ), but soon afterwards it was promoted (Supplemental Fig. 5

E). Moreover, transcriptional levels of $C Y P 1 B 1, C Y P 2 B 6$, and $C Y P 4 A 11$ were also found to be altered in HepG2 cells after MC-LR exposure (Supplemental Fig. 5 C, D, and F). However, MC-LR did not affect the mRNA levels of CYP 1A1 or CYP1A2 (Supplemental Fig. 5 A, B).

The mRNA levels of GSTM4 are shown in Fig. 2 B, in which the transcription as a whole was suppressed in the MC-LR-exposed cells. Moreover, the transcription suppression was intense with the increase of MC-LR concentrations absorbed by in HepG2 cells. The altered EPHX1 (Supplemental Fig. 6 A) and SULT1A1 (Supplemental Fig. 6 B) transcriptional levels were similar to that of GSTM4, while there was no statistically significant difference in UGT1A1 between the treatment groups and control group (Supplemental Fig. 6 C). The NAT1 expression rate in the $10000 \mathrm{nM}$ group was remarkably up-regulated after MC-LR exposure. In contrast, mRNA levels of NAT1 in the lower concentration groups were significantly lower than that of the control group, as seen in $1000 \mathrm{nM}$ group at 12 or $24 \mathrm{~h}$ (Supplemental Fig. 6 D).

3.4. The transcriptional alteration of export pump genes in HepG2 cells after 24 hof MC-LR exposure

The expression of both MRPI and MDRl at the mRNA level was mainly promoted in the MC-LR-exposed cells at higher concentrations when compared to that of control cells, for example, 1000,5000 , or $10000 \mathrm{nM}$ of MC-LR as shown in 
Supplemental Fig. 7 A and D, while MRP2 (except for $10000 \mathrm{nM}$ at $24 \mathrm{~h}$ ) and MRP3 transcription level were generally down-regulated in the MC-LR-treated groups (Supplemental Fig. 7 B, C).

\subsection{Effects of CYP inducers on MC-LR-induced cytotoxicity and damage in HepG2} cells

The viability of HepG2 cells exposed to $5 \mu \mathrm{M}$ MC-LR with and without CYP induction is depicted in Supplemental Fig. 8 A. Cell viability significantly decreased in OME/MC-LR groups after $48 \mathrm{~h}$ of exposure and in RIF/MC-LR groups after $24 \mathrm{~h}$ of exposure, and ETH/MC-LR groups significantly decreased in cell viability from 24 to $72 \mathrm{~h}$. After $24 \mathrm{~h}$ of exposure, the 5 and $10 \mu \mathrm{M}$ MC-LR with ETH groups significantly decreased in cell viability, but no changes occurred in the MC-LR treatment groups (Fig. 3 A). Further research showed that using ETH along with $5 \mu \mathrm{M}$ MC-LR led to a significant increase of ROS generation in HepG2 cells (Fig. 3 B), and significantly increased levels of MDA after $48 \mathrm{~h}$ were also found (Supplemental Fig.

$8 \mathrm{~B})$. Moreover, the Hoechst 33342 staining assay revealed that ETH/MC-LR increased the apoptosis of HepG2 cells compared with the cells treated with MC-LR alone (Supplemental Fig. 8 C). These results indicate that the CYPs inducers plus MC-LR can make HepG2 cells more sensitive to MC-LR exposure.

\subsection{Effects of CMZ on MC-LR-induced cytotoxicity and damage in HepG2 cells} Cell viability was generally not affected at CMZ/5 $\mu$ M MC-LR (Supplemental Fig. 
MC-LR-induced cytotoxicity in the cells through the cell activity assay by MTT

(Supplemental Fig. 9 B). Cell viability increased more than $18 \%$ in CMZ/ $30 \mu \mathrm{M}$

MC-LR compared with the cells treated with MC-LR alone after $96 \mathrm{~h}$ exposure

(Supplemental Fig. 9 C). The intracellular ROS levels in the $30 \mu \mathrm{M}$ MC-LR-treated HepG2 cells were higher than those of the CMZ/30 $\mu$ M MC-LR-treated cells (Fig. 4 A). Moreover, in cultures co-incubated with the ROS scavenger L-ascorbic acid and MC-LR, the ROS levels decreased compared with the cells treated with MC-LR alone, and cellular toxicity could be partly diminished by L-ascorbic acid (Supplemental Fig.

9 D, E). $30 \mu \mathrm{M}$ MC-LR significantly increased HepG2 cells MDA levels; however, CMZ partially counteracted these effects (Fig. 4 B). MMP was higher in CMZ/30 $\mu \mathrm{M}$ MC-LR-treated HepG2 cells than in $30 \mu \mathrm{M}$ MC-LR-treated cells (Fig. 4 C). To determine whether a CYP2E1 inhibitor is able to block MC-LR-induced apoptosis in HepG2 cells, a caspase-3 activity assay was performed. The results showed that treatment with CMZ and MC-LR exposure significantly reduced caspase-3 activity compared with the cells treated with MC-LR alone (Fig. 4 D).

\section{Discussion}

Cellular viability generally represents the toxicity degree of toxicants and thus it is a key index that should be determined in cytotoxicity tests (Li et al., 2015). In this study, the results showed that $0.1-10000 \mathrm{nM}$ MC-LR failed to induce cytotoxicity in HepG2 cells after $24 \mathrm{~h}$ of exposure and no difference in the cell cycle and apoptosis 
was found between the MC-LR-treated groups and the control group assayed by flow cytometry (Supplemental Fig. 1, Fig. 2, and Fig. 3). It is known to us that MCs themselves cannot readily diffuse through the plasma membrane and enter cells without the help of any transporter located in the cell membrane due to their relatively higher molecular weight (900-1100 Da) and moderate hydrophobicity (Komatsu et al., 2007; Bieczynski et al., 2014). Previous studies have found that MC-LR is usually transported into cells via OATPs; for example, OATP1B1 and OATP1B3 are the most efficient MC-LR transporters in human hepatocytes (Hagenbuch and Gui, 2008; Kalliokoski and Niemi, 2009). However, Abe et al. (2001) reported that OATP1B1 and OATP1B3 had no transporting activity in HepG2 cells. Therefore, first it is essential for the present study to determine whether MC-LR entered HepG2 cells and whether expression of OATP1B1 and OATP1B3 could be detected in the cells. The result of a western blot assay revealed that MC-LR could enter HepG2 cells as shown in Fig. 1. Furthermore, it was observed that many protein bands could be detected by the antibody against MC-LR in HepG2 cells exposed to 1000,5000 , and $10000 \mathrm{nM}$ of MC-LR for $24 \mathrm{~h}$, suggesting that there may be other new target molecules for MC-LR in the cell aside from PP2A. For a long time, it has been generally believed that the combination of MCs with $\mathrm{PP} 2 \mathrm{~A}$ is the molecular initiating event of MC hepatotoxicity (Dawson, 1998). Therefore, these new molecules should be identified in future study because this information may be valuable for completely uncovering the molecular initiating events of MC hepatotoxicity. Meanwhile, qPCR results revealed that OATP1B1 and OATP1B3 were assuredly expressed and their 
transcription was promoted by MC-LR exposure in HepG2 cells (Supplemental Fig. 4 A, B). This result was in accordance with reports by Hilgendorf et al. (2007) and Roegner and Puschner (2014), in which they found that OATP1B1 and OATP1B3 were expressed in HepG2 cells.

CYP450s are the largest and most important heme monooxygenases among the intracellular Phase I metabolic enzymes, and they play a key role not only in catalyzing a variety of reactions and converting xenobiotics to potentially reactive products as well as making them less toxic (Juchau, 1990; Isin and Guengerich, 2007) but also in the metabolic activation of carcinogens and may be further implicated in tumor initiation, promotion, and progression (Nelson et al., 1993). Within this superfamily, the subfamilies CYP1, CYP2, and CYP3 account for the metabolization and detoxification of more than $80 \%$ of xenobiotics in animals and humans (Nelson, 2003; Singh et al., 2011). Hudder et al. (2007) noted that the mRNA levels of CYP1A2 could be induced in mice after MC exposure, and this might be specifically in response to MC-LR. However, in the present study, no significant changes were found in CYP1A1 and CYP1A2 mRNA levels in the HepG2 cells exposed to MC-LR, which is in accordance with the report by Sun et al. (2011) in which they found no changes of CYP1A1 and CYP1A2 mRNA levels in male BALB/c mice after MC-LR exposure. The CYP1B1 gene is involved in tumorigenesis (Bruno and Njar, 2007), and it is overexpressed in a variety of cancers (McKay et al., 1995; Murray et al., 1997). However, CYP1B1 gene expression has not been previously analyzed in relation to MC-LR. In this study, CYP1B1 transcription was significantly altered by 
MC-LR, indicating that CYP1B1 may potentially be one of the factors responsible for the MC-LR-related increase in hepatoma risk.

CYP2B6 is strongly expressed in human liver, where it constitutes approximately $6 \%$ of total CYP450s (Stresser and Kupfer, 1999). The transcriptional regulation of CYP2B6 is important in drug metabolism and xenobiotic toxicity (Hodgson and Rose, 2007; Wang and Tompkins, 2008). In this study, CYP2B6 expression in HepG2 cells of the treatment groups was down-regulated, thus, we presumed that down-regulation of CYP2B6 by MC-LR exposure may disturb hepatocyte metabolism and hence cause damage to HepG2 cells. Additionally, the function of CYP2B6 in MC-LR hepatotoxicity must be further investigated.

CYP2E1 plays a pivotal role in the oxidative metabolism of numerous therapeutic and environmentally important chemicals, and CYP2E1 gene expression can be a pivotal determinant of some human cancers (Feierman and Cederbaum, 1987; Umeno et al., 1988). Previous studies have noted that the CYP2E1 mRNA level could be induced in mouse liver after MC exposure and that the induction of CYP2E1 may increase the generation of ROS (Sun et al., 2011; Zhang et al., 2015). In the present study, qPCR detection showed that CYP2E1 expression was significantly increased by MC-LR exposure in HepG2 cells. This result is consistent with the report by Nong et al. (2007) in which they observed the induction of CYP2E1 by MC-LR exposure in HepG2 cells. Similarly, we also found that transcription of CYP3A4 was also promoted in HepG2 cells by MC-LR. This result is in accordance with our previous study in zebrafish (Li et al., 2013), in which MC exposure altered the transcription of 
CYP3A65 in zebrafish liver. However, it is notable that CYP3A4 transcription is suppressed in higher concentration groups at early periods of exposure (from 3 to $6 \mathrm{~h}$ ). CYP4A11 converts arachidonic acid to 20-hydroxyeicosatetraenoic acid, which has a crucial role in the modulation of cardiovascular homeostasis (Fu et al., 2012), and CYP26B1 is a novel candidate gene for carcinoma (Chen et al., 2011). In the present study, CYP4A11 and CYP26B1 transcription levels were generally up-regulated in the MC-LR-treated groups in comparison with the control. To the best of our knowledge, this is the first report regarding MC-LR effects on CYP4A11 and CYP26B1, and we supposed that CYP4A11 and CYP26B1 might be involved in the metabolism of MC-LR, which might disturb the normal biological function of HepG2 cells. In short, our result indicates that MC-LR exposure alters the expression of Phase I enzymes and may disturb the metabolism of HepG2 cells.

GST and SULTs are the key Phase II metabolic enzymes that play a pivotal role in the detoxification of xenobiotics by biotransformation. It is already known that GST is a key enzyme responsible for the detoxification of MCs in animal liver or hepatocytes (Ding et al., 2001; Takenaka, 2001). However, there has been no report about the possible function of SULTs in the detoxification or metabolism of MCs until now. In this study, we observed that the transcription levels of both GSTM4 and SULTs were significantly down-regulated in MC-LR-treated HepG2 cells at higher concentrations (e.g., 1 000, 5 000, and $10000 \mathrm{nM}$ ) when compared to the control, indicating that MC-LR could suppress the expression of GSTM4 and SULTs and that GSTM4 and SULTs might play key roles in the detoxification of MCs in HepG2 cells 
(Ding et al., 2001; Takenaka, 2001).

Microsomal epoxide hydrolase (mEH) encoded by the EPHXs gene is involved in the metabolism of numerous xenobiotics and mediates the sodium-dependent transport of bile acids (von Dippe et al., 1993; Decker et al., 2009). Naturally occurring mutations of EPHX1 have been shown to result in dysfunctional of cholesterol metabolism, signal transduction pathways, and excretion of numerous metabolized xenobiotics (Zhu et al., 2003; Monte et al., 2009). In the present study, EPHX1 expression was significantly down-regulated in MC-LR-treated HepG2 cells (Supplemental Fig. 6 A). It has been reported that the inhibition of EPHX1 expression can lead to a decrease in the transport capacity of bile acids (Zhu et al., 2003). Our result suggests that MC-LR may interfere with the metabolism of bile acid in HepG2 cells, therefore, EPHX1 might be serving to protect cells from the toxic effects of MC-LR. However, the transcriptional levels of EPHX1 were not the same as those of OATP1B1 and OATP1B3, which might be associated with the complex regulation of cellular signaling networks, and further studies are needed to determine the phenomenon. EPHX1 is localized mainly in the microsomal fraction of the endoplasmic reticulum of eukaryotic cells (Václavíková et al., 2015), the decreased expression of EPHX1 caused by MC-LR may affect the function of endoplasmic reticulum, which confirms that the endoplasmic reticulum was involved in MC-LR-mediated toxicity in HepG2 cells (Menezes et al., 2013). NAT1 is a ubiquitously expressed human arylamine N-acetyltransferase (NAT) enzyme that biotransforms various aromatic, heterocyclic amines, drugs, or environmental 
carcinogens (Dairou et al., 2005; Minchin et al., 2007). In this study, the NAT1 expression rate was also changed after MC-LR exposure, indicating that MC-LR may activate the expression of NAT1, and NAT might play an important role in the activation and detoxification of environmental carcinogens (Sim et al., 2008; Butcher and Minchin, 2012), such as MCs. UGT1A1 is a critical enzyme (encoded by the UGT1A1 gene) that is responsible for metabolism and detoxification of small lipophilic molecules such as bilirubin, hormones, and drugs (Liu et al., 2010). Our results reveal that there were no changes of UGT1A1 mRNA level at different MC-LR concentrations in HepG2 cells, suggesting that MC-LR or products might not be the ligand or substrate of UGT1A1.

Transporters such as P-glycoprotein (Pgp, MDR1, ABCB1) and multidrug resistance proteins (MRPs, $\mathrm{ABCC}$ ) are members of the ATP-binding cassette (ABC) superfamily, and they have been identified in tumor cells to resist drugs or chemicals by immediate discharge and therefore prevention of cell abidance of the drugs or chemicals (Bolhuis et al., 1997; Keppler et al., 2011; Bieczynski et al., 2014). Particularly, MRP1 is involved not only in multidrug resistance of tumor cells but also in drug distribution and hepatic detoxification (Conseil et al., 2005; Kathawala et al., 2015). However, there is no literature available regarding the effect of MCs on MRPs. Our result showed that the MRP1 mRNA level was remarkably up-regulated in HepG2 cells exposed to higher concentrations of MC-LR (from 1000 to $10000 \mathrm{nM}$ ) in comparison with the control cells (Supplemental Fig. 7 A). In addition, a very similar result was obtained in MDR1 encoding P-glycoprotein, i.e., higher 
concentrations of MC-LR up-regulated MDR1 expression in HepG2 cells as shown in Supplemental Fig. 7 D. The above results indicate that expressions of multidrug resistance genes $M R P 1$ and $M D R 1$ can be promoted by MC-LR exposure in HepG2 cells, suggesting that they may take part in cell resistance to MC-LR poisoning. However, MRP2 (except for $10000 \mathrm{nM}$ at $24 \mathrm{~h}$ ) and MRP3 transcription levels were generally down-regulated in the MC-LR-treated groups. In 2007, de Souza Votto et al. reported that MDR was partly responsible for MC insensitivity in human tumoral cells (de Souza Votto et al., 2007). Although MC-LR could enter HepG2 cells (Fig. 1) and drive ROS production in the $5 \mu \mathrm{M}$ MC-LR-treated group at $6 \mathrm{~h}$ (Fig. $3 \mathrm{~B}$ ), MC-LR may have not reached the mitochondria or perhaps was being metabolized or eliminated through export pumps prior to resulting in further toxic effects to HepG2 cells. Our results suggest that altered transcription of export pump genes may be involved in the insensitivity of HepG2 cells towards MC-LR-toxicity. However, it is not characterized which transporters are involved with MC-LR efflux, further research is needed.

The altered transcriptional levels of Phase I, Phase II, and export pump genes suggest that MC-LR-exposure may destabilize the metabolism of HepG2 cells, thus, we hypothesize that the detoxification enzyme systems play important role in the resistance of HepG2 cells to MC-LR. Our results revealed that $0.1-10000 \mathrm{nM}$ MC-LR could enter HepG2 cells but did not induce cytotoxicity upon exposure for 24 h, this might be explained by the low levels of biotransformation enzymes in HepG2 cells (Liu and Zeng, 2009). Therefore, the next step is to utilize CYPs inducers to 
verify whether biotransformation enzymes play a role in the metabolic processes of MC-LR in the HepG2 cells. In this study, the viability of HepG2 cells is influenced by $5 \mu \mathrm{M}$ MC-LR after exposure to CYP inducers, for example, the cell viability significantly decreased in OME/MC-LR groups after $48 \mathrm{~h}$ of exposure and RIF/MC-LR groups after $24 \mathrm{~h}$ of exposure, and ETH/MC-LR groups significantly decreased in cell viability from 24 to $72 \mathrm{~h}$, suggesting that CYP-induced HepG2 cells are more sensitive to MC-LR exposure. Comparison of OME, ETH, and RIF revealed that in ETH incubated cells MC-LR exposure could reduce cell viability in a time-dependent fashion (Supplemental Fig. 8 A). In cells, ETH has proved to be a very effective inducer of CYPs, such as CYP1A1, CYP1A2, CYP3A4, and particularly CYP2E1 (Roymans et al., 2005). Based on the present results, the study proceeded using ETH to further investigate the mechanisms by which HepG2 cells are more sensitive to MC-LR. The MTT assay showed that MC-LR was not toxic to cells after $24 \mathrm{~h}$ of exposure except in ETH/MC-LR groups at MC-LR concentrations above $5 \mu \mathrm{M}$ (Fig. $3 \mathrm{~A}$ ). Interestingly, we found that in comparison with MC-LR exposure alone, ETH/MC-LR treatment significantly triggered ROS generation in HepG2 cells (Fig. 3 B). One could make a reasonable case that the overexpression of CYP1A1, CYP1A2, and CYP2E1 increased ROS generation (Puntarulo and Cederbaum, 1998). Several studies have shown that oxidative stress is considered an important mechanism of MC-LR toxicity, which is known to produce a large amount of ROS modifying intracellular antioxidant enzymes and inducing lipid peroxidation (Li et al., 2003; Žegura et al., 2004). Moreover, our results also showed that MDA levels in 
ETH/MC-LR groups (48 and $72 \mathrm{~h}$ ) significantly increased compared to the control and MC-LR-treatment-alone groups (Supplemental Fig. 8 B). These results confirm the production of excessive ROS in ETH/MC-LR-treated HepG2 cells, which may induce apoptosis. Importantly, the Hoechst 33342 staining assay proved that ETH/MC-LR increased the apoptosis of HepG2 cells (Supplemental Fig. 8 C). ETH is an effective inducer of CYP2E1 (Kostrubsky et al., 1995), and CYP2E1 exhibits NADPH oxidase activity and is the most active form of ROS-generating CYP450 (Nong et al., 2007). Therefore, we hypothesize that CYP2E1 plays an important role in cellular metabolic changes of HepG2 cells caused by MC-LR.

To further investigate the role of CYP2E1 in MC-LR-induced cytotoxicity, we chose CMZ, which has been shown to a specific inhibitor of CYP2E1, to inhibit the induction of CYP2E1 at the mRNA and enzyme levels (Tindberg et al., 1996) to understand the relationship between CYP2E1 and MC-LR-induced ROS. The results showed that the cell viability was generally not affected at CMZ/5 $\mu \mathrm{M}$ MC-LR, but it increased more than $18 \%$ in CMZ/30 $\mu \mathrm{M}$ MC-LR compared with the cells treated with MC-LR alone for $96 \mathrm{~h}$ (Supplemental Fig. 9 C), suggesting that CMZ may play a role in protection against MC-LR-induced cytotoxicity. Co-incubation with the ROS scavenger L-ascorbic acid and MC-LR showed that the ROS scavenger appeared to be protective against MC-LR-induced ROS and cell death (Supplemental Fig. 9 D, E). Further study showed that CMZ decreased the elevated intracellular levels of ROS after 24, 48, and $72 \mathrm{~h}$ (Fig. 4 A), and inhibited MCLR-induced MDA levels in 24 and $48 \mathrm{~h}$ (Fig. $4 \mathrm{~B}$ ), suggesting the involvement of CYP2E1 in MCLR-induced 
cytotoxicity in HepG2 cells. The mitochondria are the most pivotal subcellular site of superoxide production and play an important role in apoptosis (Guzy et al., 2005), and MMP generally represents the integrality of mitochondria membrane (Eaton and Klaassen, 2001). Caro and Cederbaum (2004) found that MMP was decreased in the CYP2E1-expressing HepG2 cells, and the decrease shared similar characteristics with the developing toxicity. In the present study, MMP was lower in MC-LR group than in $\quad \mathrm{CMZ} / \mathrm{MC}-\mathrm{LR}$ suppresses CYP2E1 expression and neutralizes damage to mitochondria. Caspase-3 has been shown to be a pivotal regulator of apoptosis and is usually cleaved and activated during the final step of apoptosis (Martin and Green, 1995). We found that CYP2E1 inhibitor CMZ inhibited caspase-3 activity induced by MC-LR in the present study (Fig. 4 D). The result of this study indicates that CMZ protects cells from MC-LR-induced apoptosis through inhibition of CYP2E1.

\section{Conclusion} HepG2 cells via our experiments using the CYP2E1 inducer ETH and the CYP2E1 
ETH is not the specific inducer for CYP2E1, and the OME and RIF exposure also affected the cell viability caused by MC-LR, further studies are necessary to investigate the function of other metabolic enzymes and export pump genes in MC-LR metabolism.

\section{Acknowledgments}

This research was supported by the National Science Foundation of China (Grant No. 31472285), the Innovation Scientists and Technicians Troop Construction Projects of Henan Province, China (Grant No. 164200510001), the Youth Science Fund of Henan Normal University, and the Key Subjects of Biology and Ecology in Henan Province, China.

\section{References}

Abe, T., Unno, M., Onogawa, T., Tokui, T., Kondo, T.N., Nakagomi, R., Adachi, H., Fujiwara, K., Okabe, M., Suzuki, T., Nunoki, K., Sato, E., Kakyo, M., Nishio, T., Sugita, J., Asano, N., Tanemoto, M., Seki, M., Date, F., Ono, K., Kondo, Y., Shiiba, K., Suzuki, M., Ohtani, H., Shimosegawa, T., linuma, K., Nagura, H., 2001. LST-2, a human liver-specific organic anion transporter, determines methotrexate sensitivity in gastrointestinal cancers. Gastroenterology 120, 1689-1699.

Azevedo, S.M.F.O., Carmichael, W.W., Jochimsen, E.M., Rinehart, K.L., Lau, S., 
Shaw, G.R., Eaglessham, G.K., 2002. Human intoxication by microcystins during renal dialysis treatment in Caruaru-Brazil. Toxicology 181, 441-446.

Backer, L.C., McNeel, S.V., Barber, T., Kirkpatrick, B., Williams, C., Irvin, M., Zhou, Y., Johnson, T.B., Nierenberg, K., Aubel, M., LePrell, R., Chapman, A., Foss, A., Corum, S., Hill, V.R., Kieszak, S.M., Cheng, Y.-S., 2010. Recreational exposure to microcystins during algal blooms in two California lakes. Toxicon 55, 909-921.

Bieczynski, F., De Anna, J.S., Pirez, M., Brena, B.M., Villanueva, S.S., Luquet, C.M., 2014. Cellular transport of microcystin-LR in rainbow trout (Oncorhynchus mykiss) across the intestinal wall: Possible involvement of multidrug resistance-associated proteins. Aquat. Toxicol. 154, 97-106.

Bolhuis, H., van Veen, H.W., Poolman, B., Driessen, A.J.M., Konings, W.N., 1997. Mechanisms of multidrug transporters. FEMS Microbiol. Rev. 21, 55-84.

Brown, P.O., Botstein, D., 1999. Exploring the new world of the genome with DNA microarrays. Nat. Genet. 21, 33-37.

Bruno, R.D., Njar, V.C., 2007. Targeting cytochrome P450 enzymes: a new approach in anti-cancer drug development. Bioorg. Med. Chem. 15, 5047-5060.

Butcher, N.J., Minchin, R.F., 2012. Arylamine N-acetyltransferase 1: a novel drug target in cancer development. Pharmacol. Rev. 64, 147-165.

Campos, A., Vasconcelos, V., 2010. Molecular mechanism of microcystin toxicity in animal cells. Int. J. Mol. Sci. 11, 268-287.

Cantoni, L., Rozio, M., Mangolini, A., Hauri, L., Caccia, S., 2003. Hyperforin 
contributes to the hepatic CYP3A-inducing effect of Hypericum perforatum extract in the mouse. Toxicol. Sci. 75, 25-30.

Carmichael, W.W., Azevedo, S.M.F.O., An, J.S., Molica, R.J.R., Jochimsen, E.M., 
xenobiotic-metabolizing enzymes arylamine $\mathrm{N}$-acetyltransferases 1 and 2 (NAT1/NAT2) by peroxynitrite in mouse skeletal muscle cells. FEBS Lett. 579, 4719-4723.

Dawson, R.M., 1998. The toxicology of microcystins. Toxicon 7, 953-962.

de Souza Votto, A.P., Renon, V.P., Yunes, J.S., Rumjanek, V.M., Capella, M.A.M., Neto, V.M., de Freitas, M.S, Geracitano, L.A., Monserrat, J.M., Trindade, G. S., 2007. Sensitivity to microcystins: a comparative study in human cell lines with and without multidrug resistance phenotype. Cell Biol. Int. 31, 1359-1366.

Decker, M., Arand, M., Cronin, A., 2009. Mammalian epoxide hydrolases in xenobiotic metabolism and signaling. Arch. Toxicol. 83, 297-318.

Ding, W.X., Shen, H.M., Ong, C.N., 2001. Critical role of reactive oxygen species formation in microcystin-induced cytoskeleton disruption in primary cultured hepatocytes. J. Toxicol. Environ. Health. 64, 507-519.

Eaton, D.L., Klaassen, C.D., 2001. Principles of toxicology. In: Klaassen, C.D. (Ed.), Casarett \&Doull'sToxicology-The Basic Science of Poisons. McGraw Hill Press, pp. 33-77.

Feierman, D.E., Cederbaum, A.L., 1987. Increased sensitivity of the microsomal oxidation of ethanol treatment. Biochem. Pharmacol. 36, 3277-3283.

Feng, G., Abdalla, M., Li, Y., Bai, Y., 2011. NF-kappa B mediates the induction of Fas receptor and Fas ligand by microcystin-LR in HepG2 cells. Mol. Cell. Biochem. 352, 209-219.

Fu, Z., Nakayama, T., Sato, N., Izumi, Y., Kasamaki, Y., Shindo, A., Ohta, M., Soma, 

study of CYP4A11 gene and myocardial infarction. Hereditas 149, 91-98.

Funari, E., Testai, E., 2008. Human health risk assessment related to cyanotoxin exposure. Crit. Rev. Toxicol. 38, 97-125.

Giannuzzi, L., Sedan, D., Echenique, R., Andrinolo, D., 2011. An acute case of intoxication with cyanobacteria and cyanotoxins in recreational water in Salto Grande Dam, Argentina. Mar Drugs 9, 2164-2175.

Guzy, R.D., Hoyos, B., Robin, E., Chen, H., Liu, L., Mansfield, K.D., Celeste Simon, M., Hammerling, U., Schumacker, P.T., 2005. Mitochondrial complex III is required for hypoxia-induced ROS production and cellular oxygen sensing. Cell Metab. 1, 401-408.

Hagenbuch, B., Gui, C., 2008. Xenobiotic transporters of the human organic anion transporting polypeptides (OATP) family. Xenobiotica 38, 778-801.

Hilgendorf, C., Ahlin, G., Seithel, A., Artursson, P., Ungell, A.L., Karlsson, J., 2007. Expression of thirty-six drug transporter genes in human intestine, liver, kidney, and organotypic cell lines. Drug Metab. Dispos. 35, 1333-1340.

Hodgson, E., Rose, R.L., 2007. The importance of cytochrome P450 2B6 in the human metabolism of environmental chemicals. Pharmacol. Ther. 113, 420-428.

Hudder, A., Song, W., O’Shea, K.E., Walsh, P.J., 2007. Toxicogenomic evaluation of microcystin-LR treated with ultrasonic irradiation. Toxicol. Appl. Pharm. 220, 357-364.

Isin, E.M., Guengerich, F.P., 2007. Complex reactions catalyzed by cytochrome P450 
683

684

Javitt, N.B., 1990. HepG2 cells as a resource for metabolic studies: lipoprotein, cholesterol, and bile acids. FASEB J. 4, 161-168.

Jia, S.J., Jiang, D.J., Hu, C.P., Zhang, X.H., Deng, H.W., Li, Y.J., 2006.

Lysophosphatidylcholine-induced elevation of asymmetric dimethylarginine level by the NADPH oxidase pathway in endothelial cells. Vasc. Pharmacol. 44, $143-148$.

Juchau, M.R., 1990. Substrate specificities and functions of the P450 cytochromes. Life Sci. 47, 2385-2394.

Kalliokoski, A., Niemi, M., 2009. Impact of OATP transporters on pharmacokinetics. Br. J. Pharmacol. 158, 693-705.

Kathawala, R.J., Gupta, P., Ashby Jr., C.R., Chen, Z.S., 2015. The modulation of $\mathrm{ABC}$ transporter-mediated multidrug resistance in cancer: A review of the past decade. Drug Resist. Update 18, 1-17.

Keppler, D., 2011. Multidrug resistance proteins (MRPs, ABCCs): importance for pathophysiology and drug therapy. Handb. Exp. Pharmacol. 201, 299-323.

Komatsu, M., Furukawa, T., Ikeda, R., Takumi, S., Nong, Q., Aoyama, K., Akiyama, S., Keppler, D., Takeuchi, T., 2007. Involvement of mitogen activated protein kinase signaling pathways in microcystin-LR induced apoptosis after its selective uptake mediated by OATP1B1 and OATP1B3. Toxicol. Sci. 97, 407-416.

Kostrubsky, V.E., Strom, S.C., Wood, S.G., Wrighton, S.A., Sinclair, P.R., Sinclair, J.F., 1995. Ethanol and isopentanol increase CYP3A and CYP2E in primary 
Li, H.Y., Xie, P., Li, G.Y., Hao, L., Xiong, Q., 2009. In vivo study on the effects of microcystin extracts on the expression profiles of proto-oncogenes (c-fos, c-jun and c-myc) in liver, kidney and testis of male Wistar rats injected i.v. with toxins. Toxicon 53, 169-175.

Li, X., Liu, Y., Song, L., Liu, J., 2003. Responses of antioxidant systems in the hepatocytes of common carp (Cyprinus carpio L.) to the toxicity of microcystin-LR. Toxicon 42, 85-89.

Li, X., Ma, J., Fang, Q., Li, Y., 2013. Transcription alterations of microRNAs, cytochrome P4501A1 and 3A65, and AhR and PXR in the liver of zebrafish exposed to crude microcystins. Toxicon 73, 17-22.

Li, X., Ma, J., Wang, J., 2015. Cytotoxicity, oxidative stress, and apoptosis in HepG2 cells induced by ionic liquid 1-methyl-3-octylimidazolium bromide. Ecotox. Environ. Safe. 120, 342-348.

Liu, Z.H., Zeng, S., 2009. Cytotoxicity of ginkgolic acid in HepG2 cells and primary rat hepatocytes. Toxicol. Lett. 187, 131-136.

Liu, Y., Ramirez, J., House, L., Ratain, M.J., 2010. Comparison of the drug-drug interactions potential of erlotinib and gefitinib via inhibition of UDP glucuronosyltransferases. Drug Metab. Dispos. 38, 32-39.

Livak, K.J., Schmittgen, T.D., 2001. Analysis of relative gene expression data using real-time quantitative PCR and 2(-Delta Delta Ct) method. Methods 25, 402408. 
Ma, J., Feng, Y., Xie, W., Li, X., 2015a. PP2A (PR65) in silver carp: cDNA cloning and expression analysis. J. Biochem. Mol. Toxicol. 29, 399-409.

Ma, J., Liu, Y., Niu, D., Li, X., 2015b. Effects of chlorpyrifos on the transcription of CYP3A cDNA, activity of acetylcholinesterase, and oxidative stress response of goldfish (Carassius auratus). Environ. Toxicol. 30, 422-429.

Ma, J., Feng, Y., Liu, Y., Li, X., 2016. PUMA and survivin are involved in the apoptosis of HepG2 cells induced by microcystin-LR via mitochondria-mediated pathway. Chemosphere 157, 241-249.

Menezes, C., Alverca, E., Dias, E., Sam-Bento, F., Pereira, P., 2013. Involvement of endoplasmic reticulum and autophagy in microcystin-LR toxicity in Vero-E6 and HepG2 cell lines. Toxicol. In Vitro 27, 138-148.

Martin, S.J., Green, D.R., 1995. Protease activation during apoptosis: death by a thousand cuts? Cell 82, 349-352.

McKay, J.A, Melvin, W.T., Ah-See, A.K., Ewen, S.W., Greenlee, W.F., Marcus, C.B., Burke, M.D., Murray, G.I., 1995. Expression of cytochrome P450 CYP1B1 in breast cancer. FEBS Lett. 374, 270-272.

Minchin, R.F., Hanna, P.E., Dupret, J.M., Wagner, C.R., Rodrigues-Lima, F., Butcher, N.J., 2007. Arylamine N-acetyltransferase I. Int. J. Biochem. Cell Biol. 39, 1999-2005.

Monte, M.J., Marin, J.J.G., Antelo, A., Vazquez-Tato, J., 2009. Bile acids: chemistry, physiology and pathophysiology. World J. Gastroenterol. 15, 804-816.

Murray, M., Reidy, G.F., 1990. Selectivity in the inhibition of mammalian cytochrome 
Murray, G.I., Taylor, M.C., McFadyen, M.C., McKay, J.A., Greenlee, W.F., Burke, M.D., Melvin, W.T., 1997. Tumour-specific expression of cytochrome P450 CYP1B1. Cancer Res. 57, 3026-3031.

Nelson, D.R., Kamataki, T., Waxman, D.J., Guengerich, F.P., Estabrook, R.W., Feyereisen, R., Gonzalez, F.J., Coon, M.J., Gunsalus, I.C., Gotoh, O., Okuda, K., Nebert, D.W., 1993. The P450 superfamily: update on new sequences, gene mapping, accession numbers, early trivial names of enzymes, and nomenclature. DNA Cell Biol. 12, 1-51.

Nelson, D.R., 2003. Comparison of P450s from human and fugu: 420 million years of vertebrate P450 evolution. Arch. Biochem. Biophys. 409, 18-24.

Nishiwaki-Matsushima, R., Ohta, T., Nishiwaki, S., Suganuma, M., Kohyama, K., Ishikawa, T., Carmichael, W.W., Fujiki, H., 1992. Liver tumor promotion by the cyanobacterial cyclic peptide toxin microcystin-LR. J. Cancer Res. Clin. Oncol. $118,420-424$.

Nong, Q., Komatsu, M., Izumo, K., Indo, H.P., Xu, B., Aoyama, K., Majima, H.J., Horiuchi, M., Morimoto, K., Takeuchi, T., 2007. Involvement of reactive oxygen species in microcystin-LR-induced cytogenotoxicity. Free. Radic. Res. 41, $1326-1337$.

Nuwaysir, E.F., Bittner, M., Trent, J., Barerett, J.C., Afshari, C.A., 1999. Microarrays and toxicology: the advent of toxicogenomics. Mol. Carcinog. 24, 153-159.

O'Neil, J.M., Davis, T.W., Burford, M.A., Gobler, C.J., 2012. The rise of harmful 
cyanobacteria blooms: the potential roles of eutrophication and climate change. Harmful Algae 14, 313-334.

Ohkawa, H., Ohishi, N., Yagi, K., 1979. Assay for lipid peroxides in animal tissues by thiobarbituric acid reaction. Anal. Biochem. 2, 351-358.

Peckova, L., Bandouchova, H., Hilscherova, K., Damkova, V., Sedlackova, J., Vitula, F., Pikula, J., 2009. Biochemical responses of juvenile and adult Japanese quails to cyanobacterial biomass. Neuroendocrinol. Lett. 30, 199.

Puntarulo, S., Cederbaum, A.I., 1998. Production of reactive oxygen species by microsomes enriched in specific human cytochrome P450 enzymes. Free Radic. Biol. Med. 24, 1324-1330.

Rastogi, R.P., Sinha, R.P., Incharoensakdi, A., 2014. The cyanotoxin-microcystins: current overview. Rev. Environ. Sci. Bio. Technol. 13, 215-249.

Roegner, A.F., Puschner, B., 2014. Aggregate culture: a more accurate predictor of microcystin toxicity for risk assessment. Toxicon $83,1-14$.

Roymans, D., Annaert, P., Van Houdt, J., Weygers, A., Noukens, J., Sensenhauser, C., Silva, J., Van Looveren, C., Hendrickx, J., Mannens, G., Meuldermans, W., 2005. Expression and induction potential of cytochromes P450 in human cryopreserved hepatocytes. Drug Metab. Dispos. 33, 1004-1016.

Runnegar, M.T., Kong, S., Berndt, N., 1993. Protein phosphatase inhibition and in vivo hepatotoxicity of microcystins. Am. J. Physiol. 265, 224-230.

Schmidt, C.W., 2002. Toxicogenomics: an emerging discipline. Environ. Health Perspect. 110, 750-755. 
Sim, E., Walters, K., Boukouvala, S., 2008. Arylamine N-acetyltransferases: from structure to function. Drug Metab. Rev. 40, 479-510.

Singh, D., Kashyap, A., Pandey, R.V., Saini, K.S., 2011. Novel advances in cytochrome P450 research. Drug Discov. Today 16, 793-799.

Song, L., Chen, W., Peng, L., Wan, N., Gan, N., Zhang, X., 2007. Distribution and bioaccumulation of microcystins in water columns: a systematic investigation into the environmental fate and the risks associated with microcystins in Meiliang Bay, Lake Taihu. Water Res. 41, 2853-2864.

Stresser, D.M., Kupfer, D., 1999. Monospecific antipeptide antibody to cytochrome P-450 2B6. Drug Metab. Dispos. 27, 517-525.

Sun, X., Mi, L., Liu, J., Song, L., Chung, F.-L., Gan, N., 2011. Sulforaphane prevents microcystin-LR-induced oxidative damage and apoptosis in BALB/c mice. Toxicol. Appl. Pharmacol. 255, 9-17.

Takenaka, S., 2001. Covalent glutathione conjugation to cyanobacterial hepatotoxin microcystin-LR by F344 rat cytosolic and microsomal glutathione S-transferases. Environ. Toxicol. Pharmacol. 9, 135-139.

Tindberg, N., Baldwin, H.A., Cross, A.J., Ingelman-Sundberg, M., 1996. Induction of cytochrome P450 2E1 expression in rat and gerbil astrocytes by inflammatory factors and ischemic injury. Mol. Pharmacol. 50, 1065-1072.

Umeno, M., McBride, O.W., Yang, C.S., Gelboin, H.V., Gonzalez, F.J., 1988. Human ethanol-inducible P450IIEI: complete gene sequence, promoter characterization, chromosome mapping and cDNA-directed expression. Biochem. 27, 9006-9013. 
van Apeldoorn, M.E., van Egmond, H.P., Speijers, G.J., Bakker, G.J., 2007. Toxins of cyanobacteria. Mol. Nutr. Food Res. 51, 7-60.

Van, I.S.C., Zegers, M.M., Kok, J.W., Hoekstra, D., 1997. Segregation of glucosylceramide and sphingomyelin occurs in the apical to basolateral transcytotic route in HepG2 cells. J. Cell Biol. 137, 347-357.

Václavíková, R., Hughes, D. J., Souček, P., 2015. Microsomal epoxide hydrolase 1 (EPHX1): Gene, structure, function, and role in human disease. Gene 571, 1-8.

von Dippe, P., Amoui, M., Alves, C., Levy, D., 1993. $\mathrm{Na}^{+}$-dependent bile acid transport by hepatocytes is mediated by a protein similar to microsomal epoxide hydrolase. Am. J. Physiol. 264, 528-534.

Wang, H., Tompkins, L.M., 2008. CYP2B6: new insights into a historically overlooked cytochrome P450 isozyme. Curr. Drug Metab. 9, 598-610.

Welker, M., Von Döhren, H., 2006. Cyanobacterial peptides-nature's own combinatorial biosynthesis. FEMS Microbial. Rev. 30, 530-563.

WHO., 1998. Guidelines for drinking-water quality. Addendum to Volume 2. Health Criteria and Other Supporting Information. Word Health Organization, Genveva, Switzerland.

Xing, M.L., Wang, X.F., Xu, L.H., 2008. Alteration of proteins expression in apoptotic FL cells induced by MCLR. Environ. Toxicol. 23, 451-458.

Xu, Q., Chen, W., Gao, G., 2008. Seasonal variations in microcystin concentrations in Lake Taihu, China. Environ. Monit. Assess. 145, 75-79.

Žegura, B., Lah, T.T., Filipič, M., 2004. The role of reactive oxygen species in 

(CYP1A1, CYP2E1, and CYP3A11) in the liver of mouse induced by microcystin-LR. Toxins 7, 1102-1115. 2003. Inhibition of human m-epoxide hydrolase gene expression in a case of hypercholanemia. Biochim. Biophys. Acta 1638, 208-216.

843

844

845

846

847

848

849

850

851

852

853

854

855

856 
Table 1. Specific primers used for qPCR.

\begin{tabular}{|c|c|c|}
\hline Primer & Forward primer & Reverse primer \\
\hline OATP1B1 & GAATGCCCAAGAGATGATGCTT & AACCCAGTGCAAGTGATTTCAAT \\
\hline OАTP1B3 & GTCCAGTCATTGGCTTTGCA & CAACCCAACGAGAGTCCTTAGG \\
\hline CYP1A1 & CCACCAAGAACTGCTTAGCC & CAGCTCCAAAGAGGTCCAAG \\
\hline CYP1A2 & TCGTAAACCAGTGGCAGGT & GGTCAGGTCGACTTTCACG \\
\hline CYP1B1 & CGGCTGGATTTGGAGAACGTA & TGATCCAATTCTGCCTGCACT \\
\hline CYP2B6 & ATGGGGCACTGAAAAAGACTGA & AGAGGCGGGGACACTGAATGAC \\
\hline CYP2E1 & GCAAGAGATGCCCTACATGGA & GGGCACGAGGGTGATGAA \\
\hline CYP3A4 & TCTTCACCGTGACCCAAAGTA & CATTGGCATGAGGTTTGCTC \\
\hline CYP4A11 & ATGAAGTGTGCCTTCAGCCA & AAGGCATTCCTCACACGGG \\
\hline CYP26B1 & CACTCGCGACAAGAGCTG & GCCTCCTGGTACACGTTGAT \\
\hline GST M4 & TTTCCTCGCCTATGATGTCC & CAGACAGCCACCCTTGTGTA \\
\hline EPHX1 & TGCACATCCAGTGCACCAA & CCAGACCCACAGGAGAGTCATT \\
\hline UGT1A1 & AACTTTCTGTGCGACGTGGTT & GTCACCTCTCTCTGAAGGAATTCTG \\
\hline NAT1 & TGGGAGGATTGCATTCAGTCT & TGCTTCTTCCTGGCTTGAATTC \\
\hline SULT1A1 & GTCACCGAGCTCCCATCTTC & GTCTCCATCCCTGAGGGAATC \\
\hline MRP1 & ACCCATGAGCTTCTTTGAGC & CACCAATGACGTTGAACAGG \\
\hline MRP2 & TGAGCAAGTTTGAAACGCACAT & AGCTCTTCTCCTGCCGTCTCT \\
\hline MRP3 & GTCCGCAGAATGGACTTGAT & TCACCACTTGGGGATCATT \\
\hline MDR1 & GCCAAAGCCAAAATATCAGC & TTCCAATGTGTTCGGCATTA \\
\hline GAPDH & GAAGGTGAAGGTCGGAGTC & GAAGATGGTGATGGGATTTC \\
\hline
\end{tabular}


860 Fig.1. Detection of MC-LR entrance into cells exposed to various concentrations of

861 MC-LR for $24 \mathrm{~h}$.

862

863

MC-LR (nM)

864

0.1

100

1000

$5000 \quad 10000$

864

865

866

867

868

869

870

871

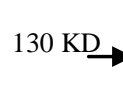
$70 \mathrm{KD}$ $42 \mathrm{KD} \rightarrow$

MC-LR

$29 \mathrm{KD}$

872

873

874

875

876

877

878

879

880

881

882 
884 Fig.2. The transcriptional alteration of CYP2E1 and GSTM4 genes in HepG2 cells

885 after $24 \mathrm{~h}$ of MC-LR-exposure.

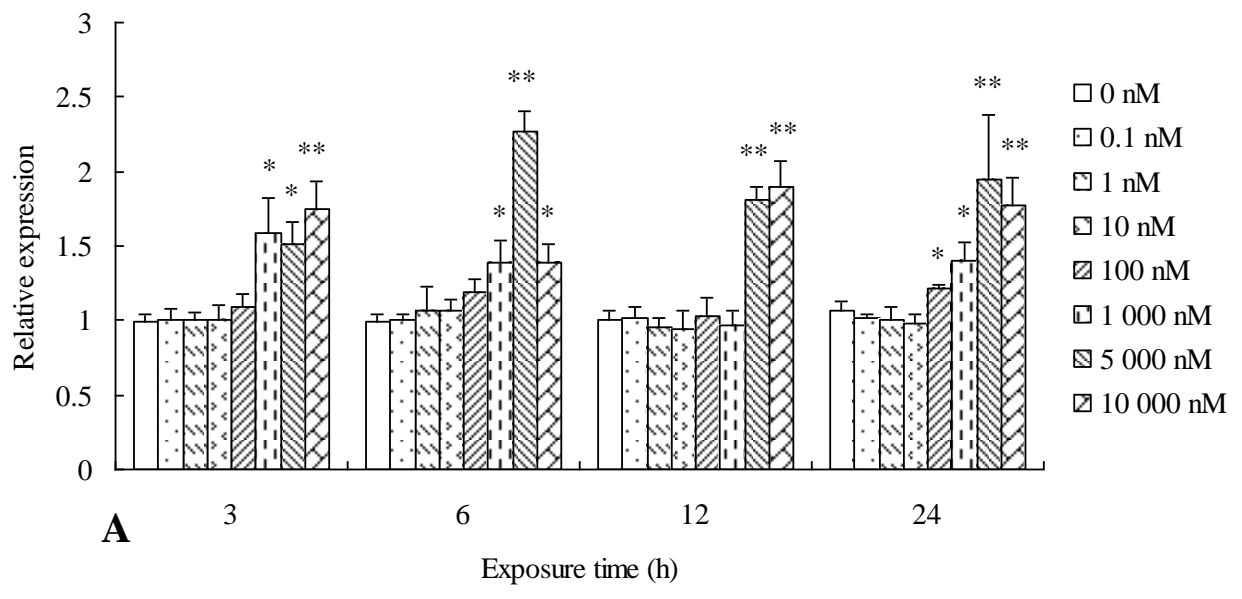

886

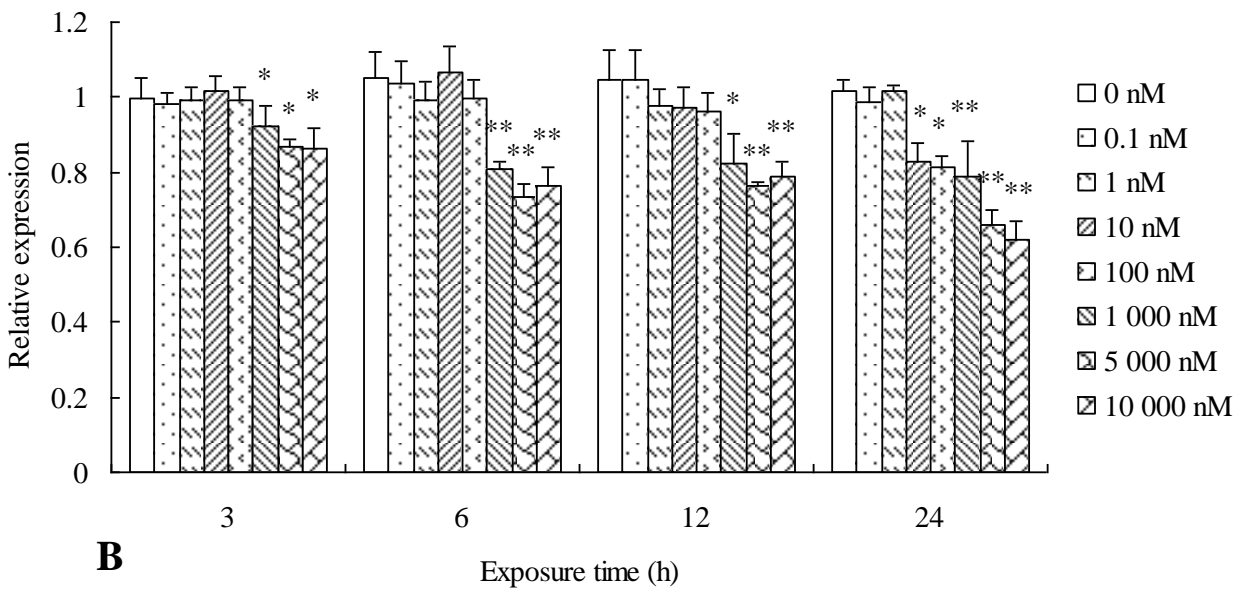

887

888

889

890

891

892

893 
897

898

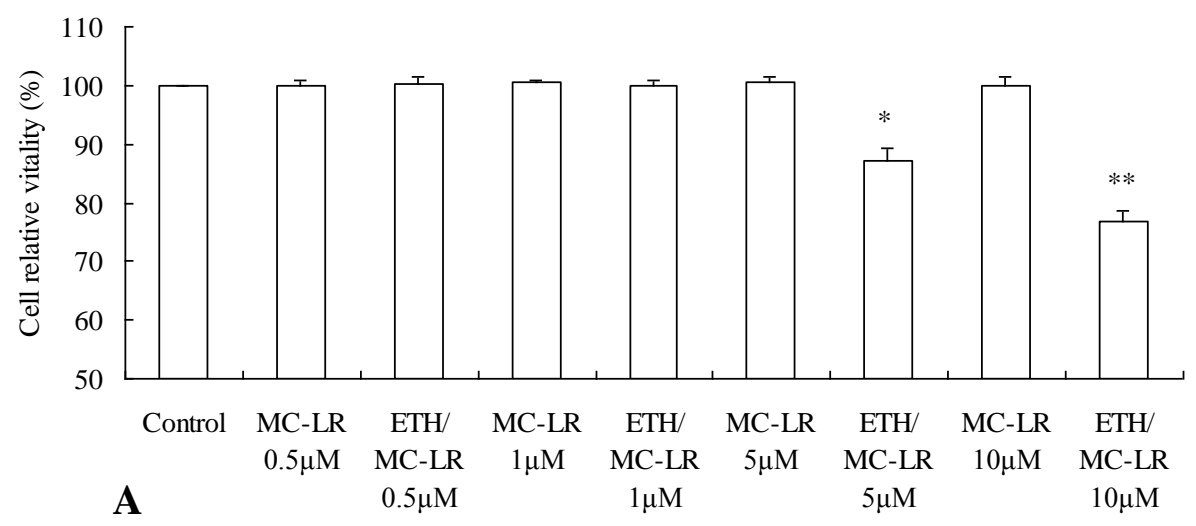

899

900

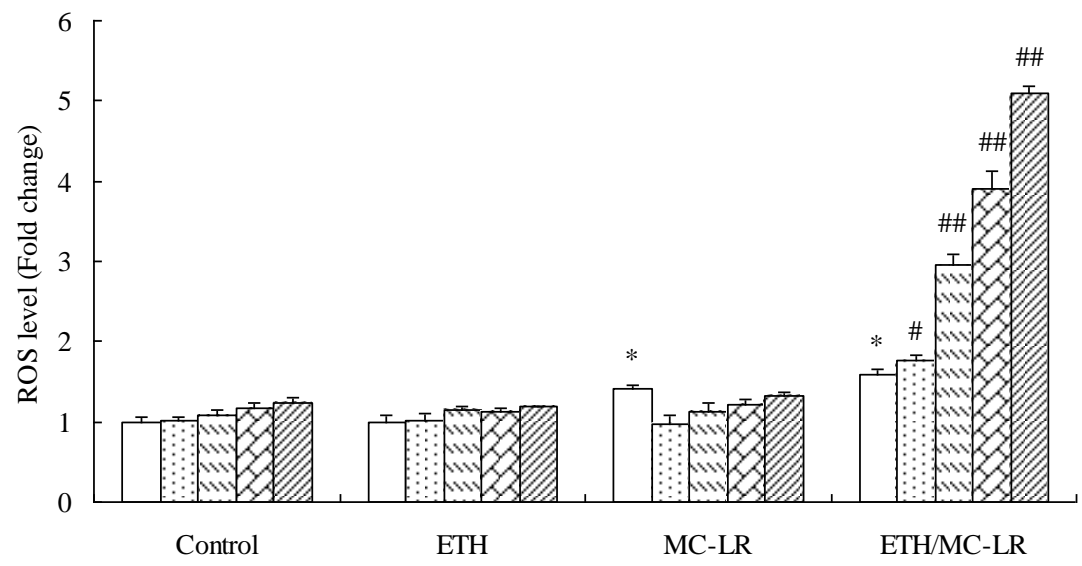

901

902

903

904

905 
908

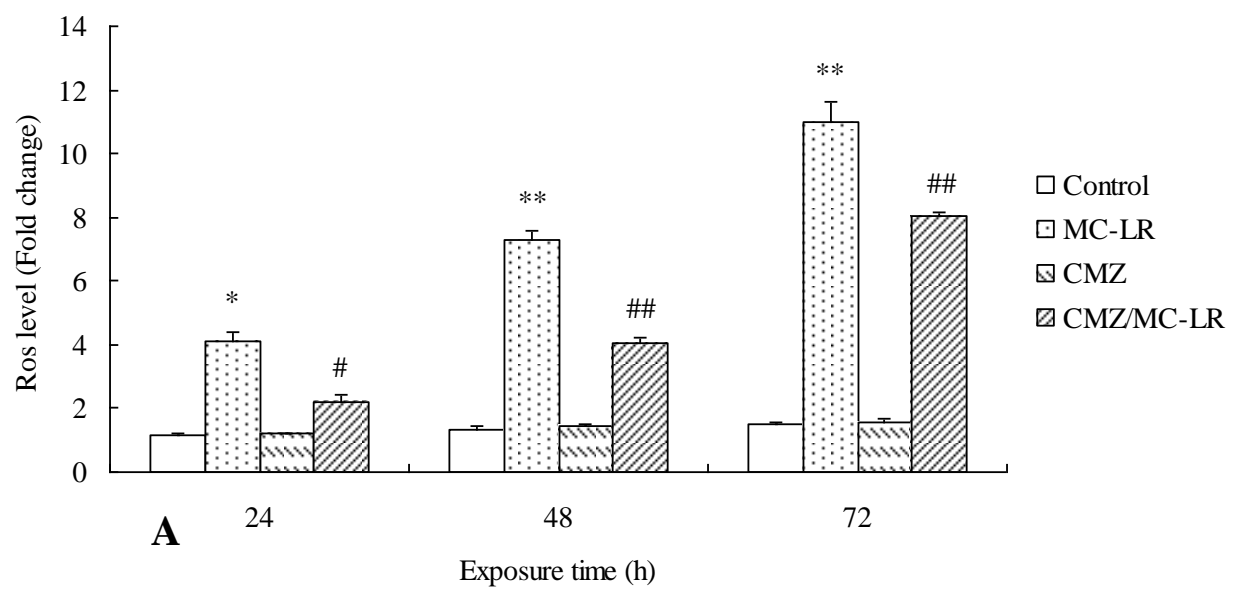

909

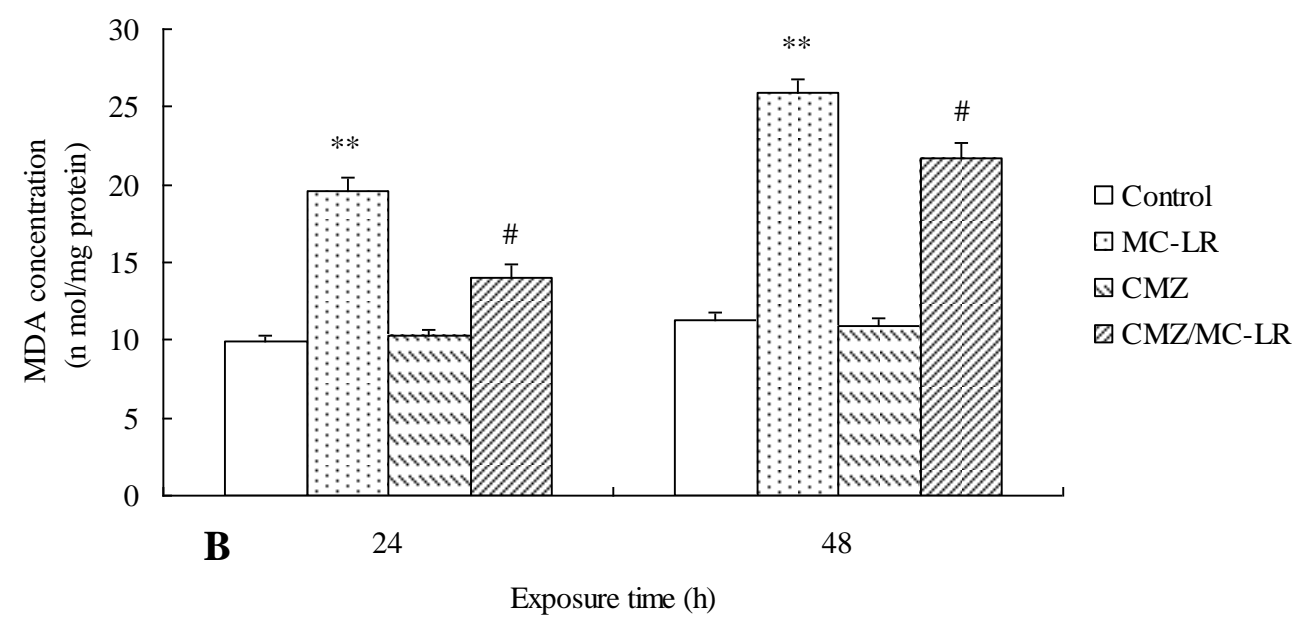

910

911
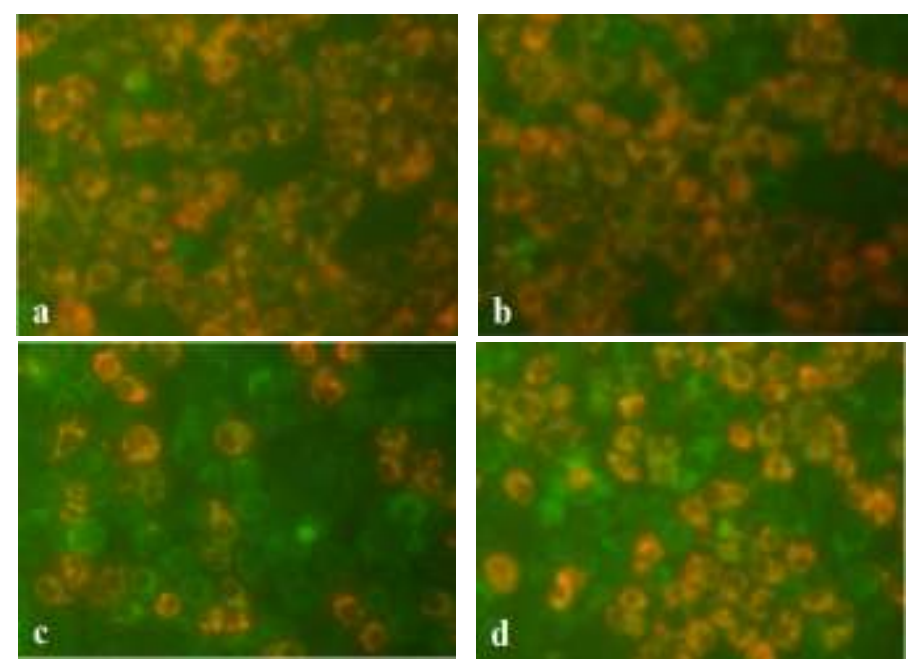

913

C 


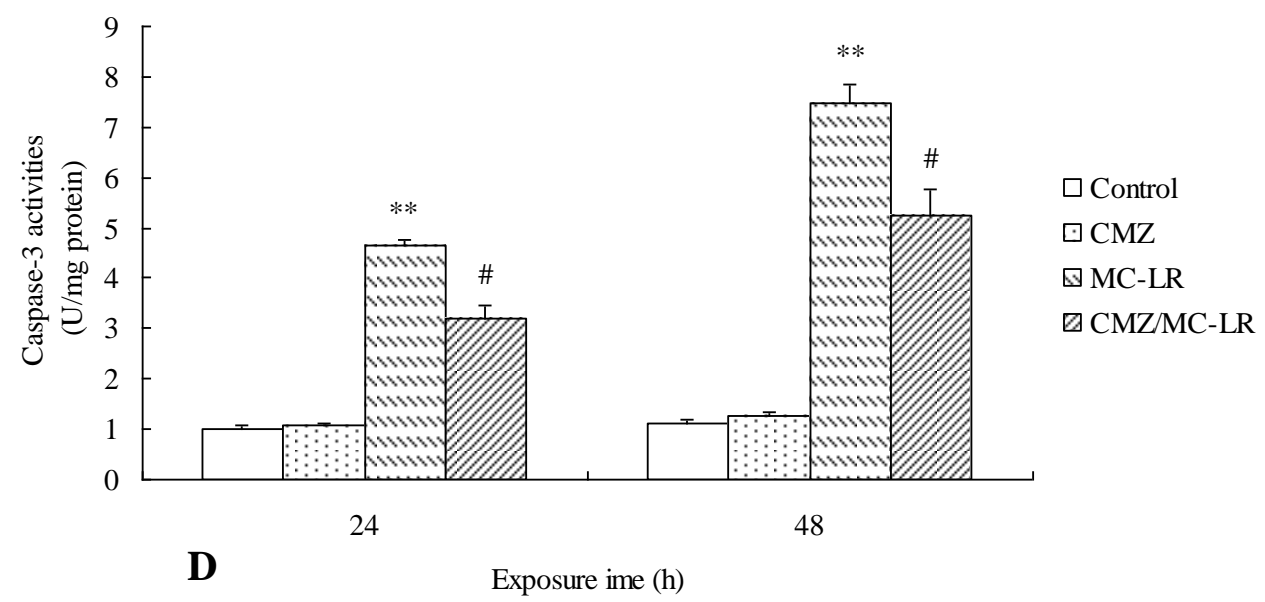

915

916

917

918

919

920

921

922

923

924

925

926

927

928

929

930 


\section{Figure Legends}

932

933

934

935

936

937

938

939

940

941

942

943

944

945

946

947

948

949

950

951

952

Fig.1. Detection of MC-LR entrance into cells exposed to various concentrations of MC-LR for $24 \mathrm{~h}$.

HepG2 cells were treated with MC-LR at various concentrations for $24 \mathrm{~h}$ and western blot assay were described in the Materials and methods. All experiments were performed in triplicate. M: marker.

Fig.2. The transcriptional alteration of CYP2E1 and GSTM4 genes in HepG2 cells after $24 \mathrm{~h}$ of MC-LR-exposure.

MC-LR exposure and qPCR performance were described in the Materials and methods. All experiments were performed in triplicate, and the data are shown as the mean \pm SD. Asterisks denote a response that is significantly different from the control $(* \mathrm{p}<0.05, * * \mathrm{p}<0.01)$. (A) CYP2E1 and (B) GSTM4.

Fig. 3. Effects of CYP inducers on MC-LR-induced cytotoxicity and damage in HepG2 cells.

MC-LR-exposure and research assay were described in the Materials and methods. All experiments were performed in triplicate, and the data are shown as the mean \pm SD. Asterisks denote a response that is significantly different from the control $\left({ }^{*} p<0.05, * * p<0.01\right)$ and hash symbol denote a response that is significantly different from the MC-LR treated alone $\left({ }^{\#} p<0.05,{ }^{\# \#} p<0.01\right)$. (A) Viability of HepG2 cells exposed to $0.5,1,5$, and $10 \mu \mathrm{M}$ MC-LR with and without ETH for $24 \mathrm{~h}$. (B) 
953

954

955

956

957

958

959

960

961

962

963

964

965

966

967

968

969

Intracellular ROS levels in HepG2 cells exposed to $5 \mu \mathrm{M}$ MC-LR with and without ETH for $72 \mathrm{~h}$.

Fig. 4. Effects of CMZ on MC-LR-induced cytotoxicity and damage in HepG2 cells. MC-LR-exposure and biochemical assays were described in the Materials and methods. All experiments were performed in triplicate, and the data are shown as the mean \pm SD. Asterisks denote a response that is significantly different from the control $\left({ }^{*} p<0.05,{ }^{*} p<0.01\right)$ and hash symbol denote a response that is significantly different from the MC-LR treated alone $\left({ }^{\#} p<0.05,{ }^{\# \#} p<0.01\right)$. (A) Intracellular ROS levels in HepG2 cells exposed to $30 \mu \mathrm{M}$ MC-LR with and without CMZ for $72 \mathrm{~h}$. (B) Intracellular contents of MDA in HepG2 cells exposed to $30 \mu \mathrm{M}$ MC-LR with and without CMZ for 48 h. (C) MMP changes in HepG2 cells incubated with $30 \mu \mathrm{M}$ MC-LR with and without CMZ for $48 \mathrm{~h}$. Red fluorescence represents the mitochondrial aggregate form of JC-1 with high MMP and green fluorescence represents the monomeric form of JC-1 with low MMP. a. control, b. CMZ (20 $\mu \mathrm{M}), \mathrm{c}$. MC-LR $(30 \mu \mathrm{M})$, d. CMZ $(20 \mu \mathrm{M}) / \mathrm{MC}-\mathrm{LR}(30 \mu \mathrm{M})$. (D) Caspase-3 activity in HepG2 cells exposed to $30 \mu \mathrm{M}$ MC-LR with and without CMZ for $48 \mathrm{~h}$. 
Graphical abstract

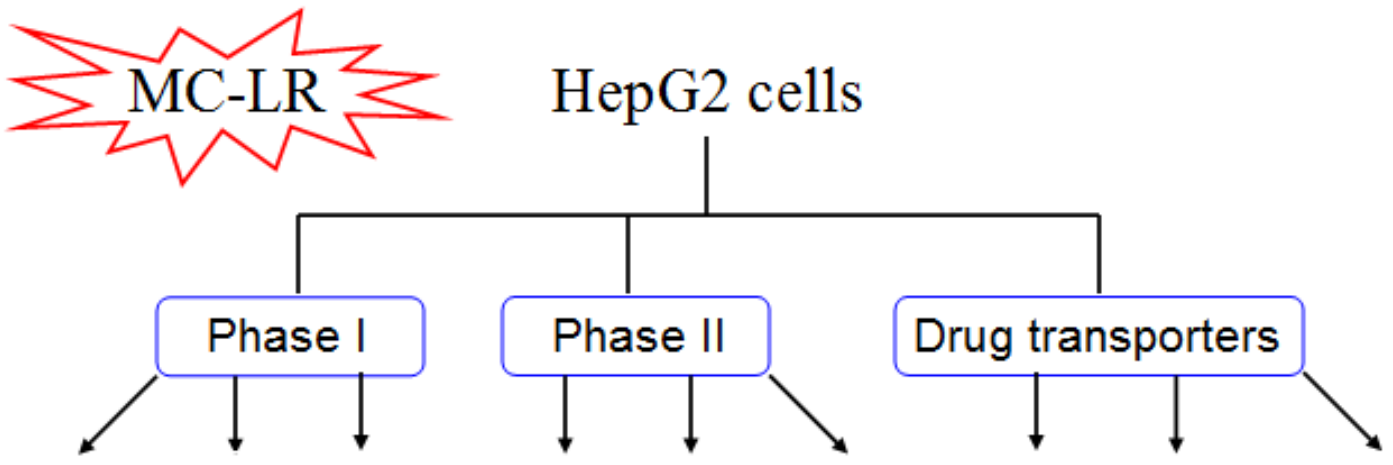

CYP1B1 CYP4A11 CYP2E1 GSTM4 NAT1 SULT1A1 MRP1 OATP1B1 MDR1

CYP2B6 CYP26B1 CYP3A4

Metabolism

\section{EPHX1}

MRP2 OATP1B3

MRP3

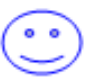

Transshipment

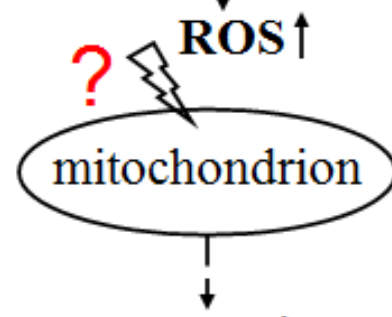

Apoptosis 